\title{
вмJ Global Health How to implement new diagnostic products in low-resource settings: an end-to-end framework
}

\author{
Melissa Latigo Mugambi, ${ }^{1}$ Trevor Peter, ${ }^{2}$ Samuel F Martins, ${ }^{3}$ Cristina Giachetti ${ }^{4}$
}

\begin{abstract}
To cite: Mugambi ML, Peter T,
F Martins S, et al. How to implement new diagnostic products in low-resource settings: an end-to-end framework. BMJ Glob Health 2018;3:e000914. doi:10.1136/ bmjgh-2018-000914
\end{abstract}

Handling editor Seye Abimbola

Received 24 April 2018

Revised 27 September 2018

Accepted 28 September 2018

Check for updates

(c) Author(s) (or their employer(s)) 2018. Re-use permitted under CC BY-NC. No commercial re-use. See rights and permissions. Published by BMJ.

'Department of Global Health, University of Washington, Seattle, Washington, USA

${ }^{2}$ Clinton Health Access Initiative, Boston, Massachusetts, USA

${ }^{3}$ Bill and Melinda Gates

Foundation, Seattle, Washington, USA

${ }^{4}$ AdvantDx, San Diego,

California, USA

Correspondence to Dr Melissa Latigo Mugambi; mugambi@uw.edu

\section{ABSTRACT}

Diagnostics developers often face challenges introducing in-vitro diagnostic (IVD) products to low- and middleincome countries (LMICs) because of difficulty in accessing robust market data, navigating policy and regulatory requirements and implementing and supporting products in healthcare systems with limited infrastructure. Best practices recommend the use of a phase-gate model with defined activities and milestones by phase to successfully move a product from concept to commercialisation. While activities for commercialisation of products in highincome countries (HICs) are well understood, the activities required for introduction of IVDs in LMICs are not. In this paper, we identify the key activities needed for IVD product development and implementation and map them to the various phases of the model, paying particular attention to those activities that might be conducted differently in LMICs.

\section{INTRODUCTION}

Recent advances in global health have highlighted the importance of improving the capacity to diagnose, monitor and prevent diseases that cause a considerable health burden. In-vitro diagnostic (IVD) tools that test human samples (eg, blood, urine or saliva) in a clinical laboratory setting or at the point of care play an important role in this context. $^{1-3}$

Despite the importance of diagnostic tools, nascent diagnostics markets in low-resource settings can present considerable challenges in the design, testing, implementation and scale-up of diagnostic products. Diagnostics developers from high-income countries (HICs) often struggle with identifying and assessing end-user needs, navigating policy and regulatory requirements, developing pricing strategies, ascertaining funding mechanisms and implementing and supporting products in healthcare systems with limited infrastructure. ${ }^{45} \mathrm{~A}$ structured approach to product development that creates more clarity around the types of activities required in low- and middle-income countries (LMICs)
Summary box

The phase-gate model for in-vitro diagnostics (IVD) product development typically comprises five stages that are used to move a product from concept to commercialisation: concept, feasibility and planning, design and development, validation and approval and launch.

- There tends to be more clarity about how the activities specific to each phase should be conducted for commercialising IVD products in high-income countries (HICs) compared with low- and middle-income countries (LMICS).

- Some of the activities characteristic of LMICs include developing policy-maker and funder engagement strategies, developing global access strategies to ensure broad accessibility of IVD products and obtaining WHO prequalification as part of the regulatory approval process

- Most of these activities have necessarily been informed by the diseases championed by influential funders, but efforts need to be extended to the broader range of IVDs.

could help developers better navigate these challenges. ${ }^{6}$

In established markets, developers typically use a phase-gate model to successfully manage how a product is moved from concept to commercialisation. ${ }^{78}$ Most phase-gate models include five basic phases: concept (phase 0), feasibility and planning (phase 1), design and development (phase 2), validation and approval (phase 3) and launch (phase 4). ${ }^{8}$ The phase-gate model identifies the key activities, decision points and decision criteria to move a product from one phase to the next. While the process used by developers might vary (eg, developers might adopt more phases by splitting some, use less phases by collapsing them or use different names for the phases), this basic organisation of the key activities is also fundamental to the development of new diagnostic products targeting less-established markets in LMICs. 
Despite the phase-gate model's value in guiding the IVD product development process, it has not formally been used to elaborate on the activities required in LMICs. There is a wide range of diagnostic tests that must be conducted as part of routine care in LMICs; ${ }^{910}$ however, few of these tests are designed for effective use in these settings. Because developers increasingly view demand for diagnostics in LMICs as a significant market and have started developing products that are fit for purpose, it is important to clarify the development and implementation activities that are specific to LMICs.

We use the phase-gate model to identify and map the key activities that are strategic to product development and implementation, paying particular attention to activities that might be conducted differently in LMICs compared with HICs and to activities that have not previously been addressed by the model. Our approach leverages both a review of the literature and our collective experiences developing and implementing diagnostic products for low-resource settings and leading funding, policy and advocacy efforts to support diagnostic development and implementation in low-resource settings.

The paper is organised by the phases characteristic of the IVD product development process as described above and shown in table 1 . We summarise the product development activities (research and development, clinical and regulatory, manufacturing), the implementation activities (marketing and sales) and the policy and advocacy activities that are required to move the product from idea to launch. The value of this model lies in its provision of a complete view of critical elements involved in diagnostic implementation, from discovery through delivery, and the opportunity for stakeholders to develop more strategic approaches to improve access to effective diagnostic technologies. Readers seeking greater depth and details of these activities are encouraged to review the resources listed in box 1 .

\section{CONCEPT AND RESEARCH}

During the concept and research phase, the developer investigates the business opportunity for the potential diagnostic product and evaluates whether there is any merit in pursuing it. One of the first steps in the process is to clearly define the need for a diagnostic tool by understanding the healthcare problem: the extent of the diagnostic gap and the limitations of existing diagnostic procedures, the context in which this problem occurs, the various factors affecting it and the estimated impact of the proposed diagnostic tool. ${ }^{11}$ Estimating the impact of diagnostics, however, becomes challenging in the absence of robust data on the disease burden, patient accessibility to healthcare facilities, the characteristics of these facilities and current and future treatment practices. ${ }^{4512}$

The TB community has addressed this gap by providing a website that directs developers to online resources on the TB disease burden and treatment landscape and pipeline (see more at http://www.tbfaqs.org). Modelling studies such as the Nature series commissioned by the Bill and Melinda Gates Foundation used multiple data sources and made key assumptions in order to define the health impact of improved access to TB, pneumonia and HIV diagnostics. ${ }^{2}{ }^{12}$ As demonstrated in the particular case of TB, collective effort to interview and gather input from multiple stakeholders, including patients, clinicians, experts from national TB programme and researchers, is important in developing a better understanding of the diagnostic need. ${ }^{13}$ Once the need is defined and a product concept to meet the need is created, the developer selects the technology(ies) that will be incorporated into the product. Demonstrating initial feasibility of the technology(ies) and proof of concept is a key decision criterion to move to the next phase of development.

Market activities focus on evaluating whether there is a commercial opportunity to meet the need. The importance of identifying and understanding all key stakeholder goals and preferences cannot be overemphasised. Developers often need to engage a diverse and complex network of stakeholders in multiple global and national entities (table 2). ${ }^{11} 1415$ Given that those who might have the authority to decide whether to adopt a product are not necessarily those who purchase or use the product, ${ }^{5}$ input from all actors is critical from very early in the development process and throughout all phases. A comprehensive stakeholder analysis sets the stage for other activities, such as further understanding and defining user needs and product value propositions from different perspectives or developing policy and advocacy engagement strategies. Initial communication with WHO programme offices or national country programmes is required to identify whether there is a need for a policy change or to monitor potential policy changes that might impact how and whether to move forward with development. ${ }^{16}$

Market research is conducted to better understand the projected growth, size and share of the market(s) in which the product will be sold, how the product will be distributed to the end user, customer needs and preferences and the product's competitive advantage. ${ }^{78}$ These activities inform others, such as development of the marketing plan, user-requirements document and the business case. The business case provides evidence to justify the need for the new diagnostic product and why pursuing its development will be a viable business opportunity. Developers also prepare a financial model that provides details around the initial investment cost, projected sales, payback period and breakeven point and other investment performance considerations, such as whether the efforts of developers, are likely to yield an acceptable return on investment. Typically, the business case and financial model are updated throughout the development process as more information becomes available and the decision to continue with development is re-evaluated at the end of each development phase. 
Table 1 IVD product development and implementation activities by phase

\begin{tabular}{|c|c|c|c|c|c|}
\hline & Phase 0 & Phase 1 & Phase 2 & Phase 3 & Phase 4 \\
\hline & Concept and research & $\begin{array}{l}\text { Product feasibility, } \\
\text { definition and planning }\end{array}$ & $\begin{array}{l}\text { Design, development } \\
\text { and transfer to } \\
\text { manufacturing }\end{array}$ & $\begin{array}{l}\text { Validation, regulatory } \\
\text { approvals and first } \\
\text { launch }\end{array}$ & $\begin{array}{l}\text { Post-launch } \\
\text { surveillance and stable } \\
\text { operations }\end{array}$ \\
\hline $\begin{array}{l}\text { Main questions to be } \\
\text { answered }\end{array}$ & $\begin{array}{l}\text { What is the } \\
\text { healthcare need? } \\
\text { Is there an } \\
\text { opportunity to } \\
\text { address the need? } \\
\text { Is there a business } \\
\text { case for investment? }\end{array}$ & $\begin{array}{l}\text { Is it feasible to } \\
\text { develop a product } \\
\text { that meets the key } \\
\text { requirements? } \\
\text { How much will it } \\
\text { cost to launch the } \\
\text { product? How long } \\
\text { will it take? } \\
\text { Can the risks to } \\
\text { development be } \\
\text { mitigated? } \\
\text { Is there still a } \\
\text { business case for } \\
\text { investment? }\end{array}$ & $\begin{array}{l}\text { Does the final product } \\
\text { design meet all } \\
\text { requirements? } \\
\text { Can the product be } \\
\text { manufactured and } \\
\text { sold? } \\
\text { Is there still a } \\
\text { business case for } \\
\text { investment? }\end{array}$ & $\begin{array}{l}\text { Does the final } \\
\text { product meet } \\
\text { clinical performance } \\
\text { requirements and } \\
\text { requirements of the } \\
\text { intended user? } \\
\text { Is there demand for } \\
\text { the product? } \\
\text { Are we ready to } \\
\text { launch? }\end{array}$ & $\begin{array}{l}\text { Is the product } \\
\text { meeting safety, } \\
\text { quality and } \\
\text { performance } \\
\text { requirements? } \\
\text { Do we need to } \\
\text { make changes to } \\
\text { the product or to its } \\
\text { method of delivery? } \\
\text { Are we making } \\
\text { enough money to be } \\
\text { profitable? }\end{array}$ \\
\hline $\begin{array}{l}\text { Marketing and sales } \\
\text { activities }\end{array}$ & $\begin{array}{l}\text { Identify healthcare } \\
\text { need(s) } \\
\text { Identify and } \\
\text { understand key } \\
\text { country stakeholders } \\
\text { Conduct market } \\
\text { research } \\
\text { Work with R\&D } \\
\text { to create product } \\
\text { concept(s) } \\
\text { Build business case } \\
\text { Prepare financial } \\
\text { model }\end{array}$ & $\begin{array}{l}\text { Finalise user } \\
\text { requirements } \\
\text { document } \\
\text { Develop marketing } \\
\text { and sales plan } \\
\text { Develop global } \\
\text { access plan } \\
\text { Update business } \\
\text { case and financial } \\
\text { model }\end{array}$ & $\begin{array}{l}\text { Update marketing } \\
\text { and sales plan } \\
\text { Update global access } \\
\text { plan } \\
\text { Update business } \\
\text { case and financial } \\
\text { model }\end{array}$ & $\begin{array}{l}\text { Execute marketing } \\
\text { and sales plan } \\
\text { Finalise global access } \\
\text { plan } \\
\text { Execute first product } \\
\text { launch in-country }\end{array}$ & $\begin{array}{l}\text { Ongoing customer } \\
\text { support, training and } \\
\text { quality monitoring } \\
\text { Continue expanding } \\
\text { the market and } \\
\text { product sales }\end{array}$ \\
\hline $\begin{array}{l}\text { Research and } \\
\text { development, } \\
\text { manufacturing, regulatory } \\
\text { and legal activities }\end{array}$ & $\begin{array}{l}\text { Select technologies } \\
\text { that support product } \\
\text { concept } \\
\text { Establish proof of } \\
\text { concept }\end{array}$ & $\begin{array}{l}\text { Develop TPP and } \\
\text { define critical product } \\
\text { requirements } \\
\text { Show technical } \\
\text { feasibility against key } \\
\text { product requirements } \\
\text { and specifications } \\
\text { Prepare development } \\
\text { plans (R\&D, } \\
\text { clinical, regulatory, } \\
\text { manufacturing, } \\
\text { quality, etc.) } \\
\text { Conduct initial risk } \\
\text { assessment } \\
\text { Review/address IP }\end{array}$ & $\begin{array}{l}\text { Complete product } \\
\text { optimisation, } \\
\text { including prototype } \\
\text { evaluations and lock } \\
\text { the design } \\
\text { Perform verification } \\
\text { studies } \\
\text { Prepare } \\
\text { manufacturing } \\
\text { and quality control } \\
\text { procedures } \\
\text { Update development } \\
\text { plans } \\
\text { Risk management } \\
\text { and analysis } \\
\text { Review/address IP }\end{array}$ & $\begin{array}{l}\text { Conduct clinical } \\
\text { validation studies and } \\
\text { prepare submissions } \\
\text { for regulatory } \\
\text { approval } \\
\text { Obtain regulatory } \\
\text { approvals }\end{array}$ & $\begin{array}{l}\text { Scale-up } \\
\text { manufacturing } \\
\text { Optimise distribution } \\
\text { and supply chain } \\
\text { Complete regulatory } \\
\text { approvals and } \\
\text { registrations in other } \\
\text { countries }\end{array}$ \\
\hline $\begin{array}{l}\text { Policy and advocacy } \\
\text { activities }\end{array}$ & $\begin{array}{l}\text { Initiate } \\
\text { communication } \\
\text { with policy makers, } \\
\text { procurers and funders }\end{array}$ & $\begin{array}{l}\text { Develop policy- } \\
\text { maker, procurer and } \\
\text { funder engagement } \\
\text { plans }\end{array}$ & $\begin{array}{l}\text { Update and execute } \\
\text { engagement plans } \\
\text { Align product } \\
\text { offering with policy, } \\
\text { procurement and } \\
\text { funding guidelines }\end{array}$ & $\begin{array}{l}\text { Execute engagement } \\
\text { plans } \\
\text { Align product } \\
\text { offering with policy, } \\
\text { procurement and } \\
\text { funding guidelines } \\
\text { Support inclusion } \\
\text { of diagnostic } \\
\text { product in WHO } \\
\text { recommendation and } \\
\text { country guidelines }\end{array}$ & $\begin{array}{l}\text { Continue to } \\
\text { support inclusion of } \\
\text { diagnostic product in } \\
\text { country guidelines }\end{array}$ \\
\hline
\end{tabular}

IP, intellectual property; IVD, in-vitro diagnostics; TPP, target product profile.

\section{PRODUCT FEASIBILITY, DEFINITION AND PLANNING}

Once the decision to initiate the business opportunity is approved, the developer further defines product requirements and specifications, evaluates the feasibility of meeting these requirements and identifies and mitigates technical and commercial risks to development. Customer needs and preferences that are identified during the concept and research phase are finalised as part of the user-requirements document and translated into product requirements (also known in global health as the target product profile or TPP). The TPP specifies the use case, that is, the context in which the diagnostics will be used (target population, desired specimen type, intended use of the test in clinical decision making and healthcare level where the test will be used), and covers the key performance and operational characteristics of the product to meet the needs of the use case (eg, expected sensitivity and specificity, turnaround time for test results, throughput and physical infrastructure requirements). ${ }^{17}$

Given that elements such as manufacturability, cost, distribution and product support greatly affect success, it 
Box 1 Select resources on the diagnostic development and implementation process relevant to low-income and middle-income countries (LMICs)

- The Foundation for Innovative New Diagnostics (FIND) (https:// www.finddx.org/resources-researchers-developers/). This website provides various resources on target product profile (TPP) development, the diagnostic pipeline for select diagnostic needs (eg, TB, malaria, fever and neglected tropical diseases) and guidance on the different studies required for the WHO approval process. Developers can also obtain additional support on needs prioritisation, test development, validation and clinical trials directly from FIND.

- The International Diagnostic Centre (http://www.idc-dx.org/ themes). This website provides resources on research and development (eg, sample TPPs and diagnostic landscapes), regulatory procedures (eg, overview of country regulatory processes, sample evaluation protocols), policy and advocacy (eg, communication and advocacy strategies) and implementation activities (eg, implementation tools, quality assurance) in diagnostic development. The website includes resources specific to multiple diseases including HIV/AIDS, TB, malaria, syphilis, hepatitis and other neglected tropical diseases.

- The USAID Center for Accelerating Innovation and Impact (https:// www.usaid.gov/cii/). This website provides a number of resources that provide guidance on the development and introduction of global health products in LMICs (eg, 'Idea to Impact: A Guide to Introduction and Scale' and 'Pathways to Scale: A Guide on Business Models and Partnership Approach to Scale-up'). The website also provides project management tools that can be used alongside the guides. While the resources broadly address health products, some of the activities are useful and can be applied to diagnostics.

- The TB Diagnostics Critical Pathway (http://www.tbdxpathway.org/). This is an interactive website that identifies key steps, activities, resources and stakeholders along the TB diagnostic, development and implementation pathway.

- TB Diagnostics: Top 10 FAQs by Test Developers (http://www.tbfaqs.org). This website provides answers and links to resources in response to 10 frequently asked questions by diagnostic developers on the TB diagnostics and implementation process in LMICs.

- Key Considerations for Introducing New HIV Point-of-Care Diagnostic Technologies in National Health Systems (http://childrenandaids. org/sites/default/files/poc-toolkit/KCD_draft_English_Low-Res. pdf). This report highlights the key considerations for introducing HIV point-of-care technologies into national health systems, including policy and framework development, strategy and planning, regulations, quality assurance and data management, procurement and supply-chain management. An additional HIV Point-of-Care Diagnostics Toolkit (http://www.childrenandaids.org/index.php/ poc-toolkit-page) provides resources to guide product site selection, forecasting and supply planning and regulatory and quality assurance processes.

- The WHO In-Vitro Diagnostics and Laboratory Technology website (http://www.who.int/diagnostics_laboratory/en/) provides resources on the in-vitro diagnostic prequalification process, procurement, quality assurance and postmarket surveillance procedures. The WHO Catalogue on Health Technology Publications (http://www. who.int/medical_devices/links/med-dev2017pub-cat.pdf?ua=1) also provides links to a number of resources on needs assessments, health technology assessments and procurement and equipment maintenance practices.

Continued

\section{Box 1 Continued}

Yock, Paul G, Todd J. Brinton, Uday N. Kumar, FT Jay Watkins Lyn Denend, and Thomas M. Krummel. Biodesign: The Process of Innovating Medical Technologies. Cambridge University Press, 2015. This book helps innovators understand and navigate the biodesign process. The corresponding website (http://biodesign.stanford.edu/resources/learning/textbook-videos.html) provides helpful video resources that can be used alongside the book. While the text broadly addresses medical devices in the US setting, a number of case studies and activities described are directly relevant to LMICs and can be applied to diagnostics.

is vital at this stage to consult delivery stakeholders (manufacturers if different from developer, procurers and distributors) to create realistic TPPs that are well aligned with the real implementation and scale-up needs. ${ }^{6}$ For example, challenges around affordability might require developers to explore technologies and formats with very low manufacturing costs in order to deliver the required product performance at significantly lower prices. In order to encourage and facilitate the development of diagnostics suitable for LMICs, the WHO and international non-governmental organisations (NGOs) such as the Foundation for Innovative New Diagnostics (FIND) and PATH (formerly the Program in Applied Technology and Health) have increasingly been involved in the development and publication of diagnostics TPPs. ${ }^{18} 19$ The International Diagnostics Center has published several TPPs for HIV diagnostics on their website (http://www. idc-dx.org/themes/development-and-evaluation/targetproduct-profiles), and more recently, Médecins Sans Frontières (MSF), FIND and WHO have worked closely with end users through a consensus effort to develop a TPP for a multi-analyte platform to diagnose febrile illness (http://www.who.int/medicines/TPP_intro_ 20171122_forDistribution.pdf).

During this phase, the developer also prepares clinical and regulatory, manufacturing and marketing and sales plans to meet development and implementation milestones. The marketing and sales plan addresses the target countries or geographies in which the product will be rolled out; develops sales and distribution strategies, including customer-service options (eg, user training, external quality-assurance programmes, installation and maintenance of instrumentation, calibration and repair) ${ }^{14}$ and defines the overall marketing strategy including advocacy and stakeholder engagement plans.

Various factors influence how a product is brought to market, such as available funding, market size, probability of success, infrastructure, policy guidelines and willingness of countries to adopt the product; there is no one-size-fits-all sales and distribution strategy. Products might be sold directly to governments, global funders or procurers (eg, the Global Fund to Fight AIDS, Tuberculosis and Malaria, commonly referred to as the "Global Fund") or to NGOs that manage a network of health 
Table 2 Key stakeholders involved in introducing diagnostic products to low-resource settings

\begin{tabular}{|c|c|c|}
\hline Stakeholder category & Key role & Examples \\
\hline Regulators & $\begin{array}{l}\text { Evaluate the quality, safety and efficacy of } \\
\text { products and approve them }\end{array}$ & National regulatory authorities, WHO DxPQ* \\
\hline Policy makers & $\begin{array}{l}\text { Develop policies and guidelines to guide how } \\
\text { products are used }\end{array}$ & Ministries of health, $\mathrm{WHO}$ \\
\hline Funders & Fund programme activities & $\begin{array}{l}\text { Ministries of finance, global funders, for } \\
\text { example, the Global Fund, PEPFAR/USAID†, } \\
\text { UNITAID } \neq \text {, World Bank, DFID§ and other bilateral } \\
\text { funders }\end{array}$ \\
\hline Procurers & $\begin{array}{l}\text { Negotiate contracts and purchase products for } \\
\text { use in-country }\end{array}$ & $\begin{array}{l}\text { National procurement authorities, global funders } \\
\text { (eg, the Global Fund), UN agencies }\end{array}$ \\
\hline Suppliers & $\begin{array}{l}\text { Develop, manufacture and distribute products } \\
\text { and support the end user on ongoing bases }\end{array}$ & Diagnostics developers, manufacturers \\
\hline Implementers & $\begin{array}{l}\text { Work with developer and/or distributor to } \\
\text { implement new diagnostic tools as part of } \\
\text { disease programme activities }\end{array}$ & $\begin{array}{l}\text { Ministries of health, local government health } \\
\text { programme, implementing partners (eg, local } \\
\text { and international NGOs) }\end{array}$ \\
\hline End users & $\begin{array}{l}\text { Use the product on ongoing bases and provide } \\
\text { feedback for continuous improvements and } \\
\text { insights into the design of future products }\end{array}$ & $\begin{array}{l}\text { Healthcare providers (clinicians, clinical officers, } \\
\text { nurses, laboratorians, community health } \\
\text { workers), patients }\end{array}$ \\
\hline Technical experts & $\begin{array}{l}\text { Provide insights into the problem, evaluate } \\
\text { interventions, support creation of policy }\end{array}$ & $\begin{array}{l}\text { Academic researchers, local and international } \\
\text { NGOs, WHO }\end{array}$ \\
\hline Advocacy groups & $\begin{array}{l}\text { Advocate for improved diagnostic, treatment } \\
\text { and preventive efforts to effectively address the } \\
\text { disease burden in low-resource settings }\end{array}$ & TAG, ASLM \\
\hline
\end{tabular}

*WHO Prequalification of In-Vitro Diagnostics Programme.

†President's Emergency Plan for AIDS Relief/United States Agency for International Development.

$\ddagger$ Global health organisation under WHO that largely funds interventions to address HIV/AIDS, hepatitis, tuberculosis, malaria and reproductive, maternal, newborn and child health.

§Department for International Development.

ASLM, African Society for Laboratory Medicine; NGOs, non-governmental organisations; TAG, Treatment Action Group.

facilities. In formulating the roll out, sales and distribution and marketing plans, it is particularly useful to develop partnerships with key opinion leaders and implementers in countries that might be early adopters of the product. A comprehensive community engagement plan covering communication strategies with global and national policy makers, procurers and funders can aid in better defining in-country implementation strategies, translating policy into practice and assuring financial support. ${ }^{2021}$

The initial intellectual property (IP) review can help identify third-party patent rights that might hinder commercialisation opportunities. Mitigation strategies might involve altering design requirements or looking into licensing agreement options. ${ }^{7}$ In certain cases for which the developer receives funding for development, funders might stipulate that this type of IP information, including the developer's patent rights, are shared and managed by the funder. This ensures global access to the diagnostic product-broad accessibility of the product to target populations on appropriate price terms and in a timely manner. In such cases, developers might work together with a funder to define a global access plan in order to address factors such as IP, royalties and pricing structures that prevent access to products. ${ }^{22} 23$ The Bill and Melinda Gates Foundation is one example of a funder that works closely with developers to create global access strategies (http://globalaccess.gatesfoundation. org).

\section{DESIGN DEVELOPMENT AND TRANSFER TO MANUFACTURING}

Formal development begins after product requirements are defined, technical feasibility is demonstrated, and high-level development and commercialisation plans are formulated by all constituents and stakeholders in the process. The goal of the development phase is to develop the final product, assure its manufacturability and lock in the design so that it is ready to be tested in the hands of the intended user. Implementation activities focus on updating and executing the marketing and sales and global access plans, while paying attention to launch requirements with long lag times.

During this phase, all components of the diagnostic product (eg, hardware, software, reagents, controls and other consumables) are finalised following the standard diagnostics product design optimisation and development process and then transferred to manufacturing. During the design process, the developer identifies an optimal product design that closely meets the desired performance specifications. End users and other 
stakeholders can provide valuable feedback on the prototype instrument in order to refine its design. ${ }^{624}$ In some cases, the relative importance of different features may need to be reassessed and used to make decisions on product design priorities.

Once the product components are fully optimised and developed, they are integrated into the overall system and formally tested during the verification process to assure that technical risks are mitigated and that performance requirements are met according to pre-established specifications. Also, during this stage, manufacturing and quality control documents and procedures for all components of the system are developed so that they can be produced in a pilot plant and/or manufacturing site, and their performance is verified to assure manufacturing consistency that meets all product requirements.

\section{VALIDATION, REGULATORY APPROVALS AND FIRST LAUNCH}

As the product enters the validation and regulatory approvals phase, the developer conducts multiple activities required for product launch: (1) conducting clinical validation studies and preparing submissions for regulatory approval; (2) aligning the product offering with the policies, guidelines and mechanisms of WHO, the country and the procurement agency and (3) executing the marketing and sales plan.

Regulatory pathways for diagnostic products targeted for LMICs are complex. The first step involves conducting clinical validation studies to generate the data required for regulatory approval to complement the in-house analytical studies. The clinical studies, conducted at LMIC clinical sites, demonstrate that the final product meets the clinical performance requirements and the requirements of the intended user. Developers selling into HICs initially obtain approval from stringent regulatory authorities (SRAs), as defined by the International Medical Device Regulators Forum (previously the Global Harmonization Taskforce; see http://www.imdrf.org/). Examples of SRAs include the Food and Drug Administration (USA) or the European Commission Directorate General (European Union), which oversees Conformitée Européene (CE) marking certification. SRAs provide regulatory approval of IVDs to be commercialised in their areas of jurisdiction.

The WHO Prequalification of In-Vitro Diagnostics Program (WHO DxPQ) provides global assurance on product quality, safety and performance in LMICs for (1) the UN and other procurement agencies to guide their purchasing decisions and (2) country national regulatory authorities that might not have sufficient capacity to fully evaluate the products and manufacturing sites. The WHO DxPQ process was recently revised; under the new process, products that are approved by an SRA have access to an expedited prequalification route. Presently, not all diagnostic products are assessed by the WHO DxPQ mechanism. For example, in the case of TB, diagnostic products are evaluated and endorsed by the WHO
Strategic and Technical Advisory Group for Tuberculosis (STAG-TB). ${ }^{25} 26$

In order to access LMIC markets, developers will increasingly need to register their products locally. The legal and policy framework and capacity for the regulation of diagnostic products in low-resource settings is still evolving. Regulatory standards and processes vary from country to country, which range from those with no formal system reliant on UN or other approvals to those with a well-resourced SRA. In many countries, local registration is often informed by international approvals, but developers are frequently required to carry out independent product registrations in different countries, often with diagnostic performance evaluations conducted by country-level laboratories. This requires careful planning, since duplicative evaluations and unclear registration requirements can delay or limit product introduction in certain geographies and disincentivise supplying LMIC markets. For example, in the case of Abbott's PIMA CD4 test (previously Alere PIMA), over 20 independent evaluations were conducted within 3 years of its release. ${ }^{27}$

Overall, it should be acknowledged that work still needs to be done to better harmonise the regulatory process and to improve the criteria by which the products are evaluated to guarantee that they consistently meet their performance requirements when they are used by the intended users in the intended settings. There have been efforts to improve elements of the process by promoting regulatory harmonisation and collaborative approaches and new efforts are being pursued to expand these approaches $;^{28}$ the WHO Regulatory Systems Strengthening Program, which is tasked with providing technical support to national regulatory authorities to improve capacity, is one such initiative.

Global and in-country policies and guidelines are also prerequisites for implementation of diagnostic products in the public sector. WHO programme teams develop the global policy recommendations, indicating what types of diagnostic products should be used, by whom (type of health worker), for whom (patient population) and for what (disease indication), based on a systematic review and grading of the evidence. ${ }^{29}$ The recently released WHO Essential Diagnostics List is also likely to play an increasing role in setting priorities for which test types are procured and implemented at the country level. ${ }^{30}$ The WHO also develops supporting guidelines, such as diagnostic-testing algorithms, interpretation guidance and patient-management strategies. Similarly, at the country level, national disease programmes make contextually relevant diagnostic policy recommendations and practice guidelines that can be adopted by the clinical community and can inform the implementation plan. Ministries of health, working with implementing and development partners, define the key activities, resources, roles and responsibilities required to prepare the country's health system for a new product (table 3 ).$^{31}$

Although development of a WHO diagnostic policy sometimes precedes and influences a country's 
Table 3 Elements required for product launch

\begin{tabular}{ll}
\hline Item & Description \\
\hline $\begin{array}{l}\text { Policy, guidelines and } \\
\text { product registration }\end{array}$ & $\begin{array}{l}\text { Officially decide to adopt the diagnostic intervention and develop practice guidelines to inform } \\
\text { the implementation process; legally approve products that meet the required quality, safety and } \\
\text { efficacy standards. }\end{array}$ \\
$\begin{array}{l}\text { Site selection and health } \\
\text { facility infrastructure }\end{array}$ & $\begin{array}{l}\text { Select clinical sites per product rollout strategy to optimally integrate the new product into } \\
\text { workflows; update health facilities to meet product installation and operational requirements. }\end{array}$ \\
$\begin{array}{l}\text { Financing, procurement } \\
\text { and supply and distribution } \\
\text { logistics }\end{array}$ & $\begin{array}{l}\text { Identify secure sources of funding to cover procurement, implementation and maintenance } \\
\text { costs; define forecasting and ordering processes and identify suppliers; identify, coordinate and } \\
\text { monitor key players in the supply and distribution process. }\end{array}$ \\
$\begin{array}{l}\text { Quality management system } \\
\text { Establish laboratory or health facility quality management system relevant to the diagnostic } \\
\text { test that covers personnel training and supervision, record keeping, equipment service and } \\
\text { maintenance plan and corrective-action and preventive-action procedures. }\end{array}$ \\
$\begin{array}{l}\text { Monitoring, reporting and } \\
\text { evaluation }\end{array}$ & $\begin{array}{l}\text { Define } \\
\text { and other administrative registers to accommodate new reporting requirements and metrics; } \\
\text { support streamlined collection, storage, auditing and communication of data. }\end{array}$ \\
\hline
\end{tabular}

policy-development process, other factors may also play a role. These include local policies and laws that have implications for determining the types of tests that are used at a particular health facility level and by whom; local evidence of diagnostic performance and impact; adoption of intervention by countries that are considered 'catalysts' or 'early adopters'; funding availability; technical capacity and presence of local advocates or champions. Note that in the case of a similar testing method, a new policy might not be needed; tests need only be registered or approved for use. If this is not the case, the manufacturer must work closely with the authorities to confirm that policies are in place to support the product launch.

There are multiple mechanisms by which diagnostic products can be procured and supplied, and developers will execute a product introduction and a marketing and sales plan based on target markets and procurers. While sale contracts in the private sector typically follow standard commercial rules, public-sector sale and distribution contracts are more complex and depend on the source of funds and the product demand. Public diagnostic procurement activities largely centre on HIV/AIDS, TB and malaria, which have well-established programmes that are mostly funded by national governments, with support from the Global Fund, the US government through the US President's Emergency Plan for AIDS Relief (PEPFAR) and the US President's Malaria Initiative (PMI), UN agencies and UNITAID (a global health organisation under WHO that largely funds interventions to address HIV/AIDS, hepatitis, tuberculosis, malaria and reproductive, maternal, newborn and child health).

Governments either obtain funding from local sources or from funders for wide-scale diagnostic publicsector procurement, creating very particular marketing dynamics for these diseases. ${ }^{20}$ Public-sector procurement usually follows a tender and bidding process that is governed by local legislation and/or funder regulations, if applicable. National procurement authorities are responsible for the procurement, storage and distribution of diagnostic products. Multiple distribution models exist whereby products are directly or indirectly distributed to health facilities, for example, through an intermediary such as district-level hospitals or private contractors. ${ }^{32}$

The Global Fund primarily awards grants to countries for the procurement of HIV, TB and malaria diagnostics that meet the Global Fund quality requirements (eg, WHO DxPQ, SRA approval or approval from an expert review panel). Depending on the nature of the grant agreement, countries can use their own procurement authorities and systems, select a procurement agent through a competitive process, use procurement agents selected by the Global Fund or participate in the Global Fund's pooled procurement mechanism. The latter enables countries to benefit from negotiated prices through the bulk order of commodities for multiple grantees.

PEPFAR funds the procurement of HIV diagnostic products for PEPFAR-supported programmes through a pooled mechanism run by contracted procurement agencies. Diagnostics can be procured if they are registered for use in-country, are included in the national guidelines and meet USAID approval criteria-WHO DxPQ, FDA approval or approval by the US Centers for Disease Control and Prevention. Additional site-specific evaluations might also be required.

\section{POST-LAUNCH SURVEILLANCE AND STABLE OPERATIONS}

Following launch of the product in the first country or countries, the developer's customer service and/or technical-support organisations continuously monitor how the product is performing in the field and provide customer training and support to ensure that the product is performing effectively. The WHO Safety and Vigilance Program tracks reports of product failures and issues notifications to users (http://www.who.int/medicines/regulation/safety-vigilance/en/). The extent of postmarket 
surveillance for diagnostic products is currently limited but is expected to grow significantly.

Market uptake activities involve the coordinated execution of the developers' marketing and sales plan according to the countries' implementation plans (table 3). Integration and coordination of stakeholder activities is important for streamlining the implementation process to support an efficient scale-up. Manufacturing and distribution processes are optimised to improve overall performance from the commercial side. Pilot studies may initially be conducted as an opportunity for countries to evaluate the diagnostic intervention in an operational setting and to adjust the implementation plan as needed prior to scaling up to a larger number of health facilities. The experiences of early adopters and detailed analysis of positive and negative outcomes provide critical insights for the further implementation and scale-up of the product. ${ }^{20}$

Market uptake activities can often take years before the intervention is routinely integrated into practice. It is therefore critical to keep stakeholders engaged and to rapidly deliver results. This also serves as a useful strategy to attract more funding, given that scale-up and maintenance can be quite costly. Furthermore, ensuring ongoing supply of diagnostic products within the public sector requires routine forecasting and procurement planning by national laboratory departments, as well as innovation in procurement agreements. This is often conducted on an annual basis and in certain circumstances is supported by implementing partners and supply-chain experts. Novel supply-agreement mechanisms in LMICs—such as reagent rentals for instrument-based tests and long-term agreements-to support large-scale procurement of diagnostic products have been developed and implemented by partnerships among developers, implementers and funders. These are designed to mitigate risks for both developers and purchasers, and they require collaboration and partnership.

\section{CONCLUSION}

The specific conditions and needs of nascent markets in LMICs, such as lack of access to robust data, limited health infrastructure and supply distribution networks and limited capacity for regulation of diagnostic devices, shape the activities required for product development and implementation. While the IVD development phasegate process has shown to be an effective management tool to map out and execute the activities needed to move a product from concept to commercialisation, developers often struggle with product introduction efforts in LMICs since little information is readily available to understand the activities unique to LMICs and how they should be conducted.

With mounting advocacy pressures to effectively address high-burden diseases in under-resourced settings, global policy makers and funders have become increasingly involved in shaping the market to enable access to low-cost diagnostic tools that are tailored to the conditions and needs in LMICs. However, most of these efforts have been focused on infectious diseases and siloed within vertical disease programmes for HIV, TB and malaria, resulting in more consensus around the diagnostics development and implementation activities for these diseases. Efforts need to be broadened to include the full range of diagnostics that typically have not been championed by influential funders. As some of the fundamental barriers to market entry are addressed-for example, through initiatives that improve access to data or harmonise regulatory process across different regions-this is likely to influence the developer's interest and approach to the introduction of new products in LMICs.

The pathway to successful scale-up of diagnostic interventions requires deep understanding and detailed end-to-end planning of the activities required as well as continuous coordination of the various stakeholders involved in the diagnostics development and implementation process. While we attempt to provide clarity to the process by describing and organising the activities that need to be addressed in LMICs, a well-functioning delivery system that includes laboratory networks, supply logistics and quality management is needed to ensure sustained scale-up. Ultimately, a strong commitment from authorities and a consistent, robust source of funding for diagnostics more broadly is essential.

Acknowledgements We would like to thank Richard Feit for copyediting a draft of the paper and Shyam Bhaskaran (Bill and Melinda Gates Foundation) for his helpful comments on the paper.

Contributors MLM wrote the first draft of this paper with substantial input from CG. All authors (MLM, TP, SDFM, CG) provided critical input on subsequent drafts.

Funding The authors have not declared a specific grant for this research from any funding agency in the public, commercial or not-for-profit sectors.

Competing interests None declared.

Patient consent Not required.

Provenance and peer review Not commissioned; externally peer reviewed.

Data sharing statement № additional data are available.

Open access This is an open access article distributed in accordance with the Creative Commons Attribution Non Commercial (CC BY-NC 4.0) license, which permits others to distribute, remix, adapt, build upon this work non-commercially, and license their derivative works on different terms, provided the original work is properly cited, appropriate credit is given, any changes made indicated, and the use is non-commercial. See: http://creativecommons.org/licenses/by-nc/4.0/

\section{REFERENCES}

1. Schroeder LF, Guarner J, Elbireer A, et al. Time for a model list of essential diagnostics. N Engl J Med 2016;374:2511-4.

2. Hay Burgess DC, Wasserman J, Dahl CA. Global health diagnostics. Nature 2006;444(Suppl 1):1-2.

3. Wilson ML, Fleming KA, Kuti MA, et al. Access to pathology and laboratory medicine services: a crucial gap. Lancet 2018;391:1927-38.

4. Pai M. Diagnostics for tuberculosis: what test developers want to know. Expert Rev Mol Diagn 2013;13:311-4.

5. Free MJ. Achieving appropriate design and widespread use of health care technologies in the developing world. Overcoming obstacles that impede the adaptation and diffusion of priority technologies for primary health care. Int J Gynaecol Obstet 2004;85(Suppl 1):S3-13.

6. Engel N, Wachter K, Pai M, et al. Addressing the challenges of diagnostics demand and supply: insights from an online global health discussion platform. BMJ Glob Health 2016;1:e000132. 
7. Pietzsch JB, Shluzas LA, Paté-Cornell ME, et al. Stage-gate process for the development of medical devices. J Med Device 2009;3:021004.

8. Kern D, Ward DM. The role of project management in the development of in vitro diagnostics. Pharmaceutical and biomedical project management in a changing global environment. Wiley 2011;11:53.

9. Schroeder LF, Guarner J, Amukele TK. Essential diagnostics for the use of World Health Organization essential medicines. Clin Chem 2018;64:1148-57.

10. Fleming KA, Naidoo M, Wilson M, et al. An essential pathology package for low- and middle-income countries. Am J Clin Pathol 2017:147:15-32.

11. Weigl BH, Gaydos CA, Kost G, et al. The value of clinical needs assessments for point-of-care diagnostics. Point Care 2012;11:108-13.

12. Girosi F, Olmsted SS, Keeler E, et al. Developing and interpreting models to improve diagnostics in developing countries. Nature 2006;444(Suppl 1):3-8.

13. Denkinger CM, Kik SV, Cirillo DM, et al. Defining the needs for next generation assays for tuberculosis. $J$ Infect Dis 2015;211(suppl_2):S29-38.

14. Yock PG, Zenios S, Makower J. Biodesign. Cambridge: Cambridge University Press, 2015.

15. Mugambi ML, Palamountain KM, Gallarda J, et al. Exploring the case for a global alliance for medical diagnostics initiative. Diagnostics 2017;7:8.

16. USAID. Idea to impact: a guide to introduction and scale of global health innovations. 2015. Available from: www.usaid.gov/cii

17. Kik SV, Denkinger CM, Casenghi M, et al. Tuberculosis diagnostics: which target product profiles should be prioritised? Eur Respir J 2014;44:537-40.

18. World Health Organization. High priority target product profiles for new tuberculosis diagnostics: report of a consensus meeting, 28-29 April. Geneva, Switzerland: World Health Organization, 2014.

19. Porrás Al, Yadon ZE, Altcheh J, et al. Target product profile (TPP) for Chagas disease point-of-care diagnosis and assessment of response to treatment. PLoS Negl Trop Dis 2015;9:e0003697.

20. Albert $\mathrm{H}$, Nathavitharana RR, Isaacs $\mathrm{C}$, et al. Development, roll-out and impact of Xpert MTB/RIF for tuberculosis: what lessons have we learnt and how can we do better? Eur Respir J 2016;48:ERJ-005432016.

21. Ramsay A, Steingart KR, Cunningham J, et al. Translating tuberculosis research into global policies: the example of an international collaboration on diagnostics. Int $J$ Tuberc Lung Dis 2011:15:1283-93.

22. Urdea M, Penny LA, Olmsted SS, et al. Requirements for high impact diagnostics in the developing world. Nature 2006;444(Suppl 1):73-9.

23. Chokshi DA, Rajkumar R. Leveraging university research to advance global health. JAMA 2007;298:1934-6.

24. Shah SG, Robinson I, AIShawi S. Developing medical device technologies from users' perspectives: a theoretical framework for involving users in the development process. Int $J$ Technol Assess Health Care 2009;25:514-21.

25. Morin S, Bazarova N, Jacon P, et al. The Manufacturers' perspective on World Health Organization prequalification of in vitro diagnostics. Clin Infect Dis 2018;66:301-5.

26. McNerney R. Diagnostics for developing countries. Diagnostics 2015:5:200-9.

27. Scott LE, Campbell J, Westerman L, et al. A meta-analysis of the performance of the Pima ${ }^{\mathrm{TM}} \mathrm{CD} 4$ for point of care testing. BMC Med 2015; $13: 168$

28. Rugera SP, McNerney R, Poon AK, et al. Regulation of medical diagnostics and medical devices in the East African community partner states. BMC Health Serv Res 2014;14:1.

29. World Health Organization. WHO handbook for guideline development. Geneva: World Health Organization, 2012

30. World Health Organization. World Health Organization model list of essential in vitro diagnostics, 2018. http://www.who.int/medical_ devices/diagnostics/WHO EDL 2018.pdf [accessed 10 Jul 2018]

31. World Health Organization. Xpert MTB/RIF implementation manual: technical and operational 'how-to'; practical considerations, 2014. http://www.who.int/tb/publications/xpert_implem_manual/en/ [accessed 11 Jul 2018].

32. Yadav P, Tata H, Babaley M. The world medicines situation 2011. Storage and supply chain management. Geneva: World Health Organization, 2011. 


\section{Correction: How to implement new diagnostic products in low-resource settings: an end-to-end framework}

Mugambi ML, Peter T, F Martins S, et al How to implement new diagnostic products in low-resource settings: an end-to-end framework. BMJ Global Health 2018;3:e000914. doi: 10.1136/bmjgh-2018-000914

This article has been corrected since it first published. Owing to the correction in affiliations. This is corrected in the latest version.

Open access This is an open access article distributed in accordance with the Creative Commons Attribution Non Commercial (CC BY-NC 4.0) license, which permits others to distribute, remix, adapt, build upon this work non-commercially, and license their derivative works on different terms, provided the original work is properly cited, appropriate credit is given, any changes made indicated, and the use is non-commercial. See:http://creativecommons.org/licenses/by-nc/4.0/

(C) Author(s) (or their employer(s)) 2018. Re-use permitted under CC BY-NC. No commercial re-use. See rights and permissions. Published by BMJ.

BMJ Glob Health 2018;3:e000914corr1. doi:10.1136/bmjgh-2018-000914corr1

A) Check for updates 